\title{
O lugar dos estudes franceses na constituição de uma memória da Análise de Discurso no Brasil
}

The place of French studies in the constitution of a memory of Discourse Analysis in Brazil

\author{
Amanda Eloina Scherer \\ Universidade Federal de Santa Maria, Santa Maria, RS, Brasil \\ Lucília Abrahão Sousa \\ Universidade de São Paulo, Ribeirão Preto, SP, Brasil \\ Vanise Medeiros \\ Universidade Federal Fluminense, Niterói, RJ, Brasil \\ Verli Petri
}

Universidade Federal de Santa Maria, Santa Maria, RS, Brasil

Todo leitor é marcado por uma fome e para cada leitor essa fome é uma fome diferente.

(José Castello)

Resumo: Nosso quadro teórico situa-se na sequência das reflexões propostas por Michel Pêcheux na França que ganharam um novo direcionamento no Brasil a partir dos estudos empreendidos por Eni Orlandi (Unicamp) e seu grupo de pesquisadores. A Análise de Discurso é marcada por uma dinâmica nova, assinalando outro tempo e revelando novas maneiras de ler as materialidades, o que se coloca como uma construção disciplinar bem específica no interior dos programas de formação de pesquisadores das principais universidades brasileiras. É sobre isso que nos propomos refletir, trazendo à baila noções tais como: constituição disciplinar, condições de produção, análise de discurso, memória.

Palavras-chave: Discurso. Pêcheux. Brasil. Estudos franceses. Memória.

Abstract: Our theoretical framework is located in the sequence of reflections proposed by Michel Pêcheux in France, which have gained a new direction in Brazil from the studies undertaken by Eni Orlandi (Unicamp) and her group of researchers. Discourse Analysis is marked by a new dynamic, showing another time and revealing new ways of reading the materiality, which arises as a very specific disciplinary construction inside researchers training programs leading in Brazilian universities. That is what we aim to reflect upon, bringing up notions such as disciplinary constitution, conditions of production, discourse analysis, memory.

Keywords: Discourse. Pêcheux. Brazil. French studies. Memory. 


\title{
Primeiras palavras ${ }^{1}$
}

Amanda Eloina

Scherer

Lucilia

Abrahão Sousa

Vanise Medeiros

Verli Petri

No Brasil, a disciplinarização dos estudos sobre o discurso ganhou força no final dos anos 1970 e início de 1980 e seus fundamentos teóricos advêm de fora, seja da Europa, seja pela via americana, o que coincide com o retorno de grande parte dos pesquisadores brasileiros que se encontrava fora do país tanto para complementar sua formação acadêmica quanto para "sobreviver" aos suplícios da ditadura militar que aqui se instalara. Tal disciplinarização que hoje conhecemos desenvolveu-se a partir de pesquisas elaboradas fora do campo brasileiro, mas, uma vez instalada no interior do circuito universitário, sobretudo nos programas de formação doutoral, foi tomando diferentes formas e ganhando designações bem específicas, fazendo aparecer campos de saber distintos daqueles que estavam sendo produzidos no exterior.

A disciplinarização dos estudos sobre o discurso se dá na movência dos campos e dos programas que vão dar sentido à pesquisa desenvolvida por nós e entre nós. É nesse momento também que emerge a produção de Mattoso Câmara, e nos “permettre d'assister, entre autres choses, à la constitution nette de la sémantique comme domaine disciplinaire spécifique"2 (GUIMARÃES, 2007, p. 27), bem como nos autoriza a afirmar que esse é o momento no qual as disciplinas da significação vão tomar lugar no mundo universitário brasileiro. Além disso, Guimarães nos faz igualmente destacar que

\begin{abstract}
les années 70 sont le moment fondamental de ce nouveau mouvement d'idées. Ce qui se présente à cette époque, est, d'un côté, d'une importance décisive et, de l'autre, marque le début d'un processus de production de connaissance qui se projettera sur les années suivantes et jusqu'à nos jours ${ }^{3}$ (GUIMARÃES, 2007, p. 27).
\end{abstract}

Guimarães (2007) reuniu em onze grupos os trabalhos desenvolvidos no período no qual ele inseriu os estudos sobre a Análise de

\footnotetext{
1 Uma primeira versão deste trabalho foi apresentada no $\mathrm{X}^{\mathrm{e}}$ Congrès International de Linguistique Française (CIFL), em Cadix, 2013, e resulta do enlace acadêmico de pesquisadores de três laboratórios, a saber: Corpus (PPGL/UFSM), El@dis (USP/Ribeirão Preto) e LAS (UFF).

2 "permit[e] assistir, entre outras coisas, à constituição clara da semântica como domínio disciplinar específico" (tradução nossa).

3 “os anos 70 são o momento fundamental deste novo movimento de ideias. 0 que se apresenta a essa época é, de um lado, de uma importância decisiva e, de outro, marca o início de um processo de produção de conhecimento que se projetará sobre os anos seguintes e até os nossos dias" (tradução nossa).
} 
Discurso no Brasil, sobretudo aquela chamada "de linha francesa", hoje também conhecida como a Análise de Discurso brasileira. ${ }^{4}$

A reflexão que propomos neste momento tem o objetivo de explicitar como tal movimento se historiciza e se consolida enquanto campo O lugar dos estudos de pesquisa. As questões que vão nos guiar podem ser assim apresentadas: franceses na

a) O primeiro eixo de reflexão refere-se aos questionamentos sobre constituição a disciplina de Análise de Discurso e seu quadro teórico fundador na ordem epistemológica em torno do lugar do pesquisador no Brasil e em suas relações com a transmissão e a circulação das ideias vindas da França;

b) O segundo diz respeito ao impacto e ao lugar da Análise de Discurso numa perspectiva de engajamento ideológico do analista em relação à intervenção do pesquisador nas demandas sociais em de uma memória da Análise de Discurso no Brasil voga naquele momento histórico (SCHERER; DIAS; PETRI, 2014);

c) Para o terceiro eixo de questões, propomos a discussão sobre como se pode pensar a Análise de Discurso, já com algum distanciamento, desde sua fundação até as problemáticas que ela abrange atualmente, levando em conta a teorização de sua discursividade enquanto movimento da sociedade em relação ao político da significação;

d) Por fim, para o quarto eixo, trazemos uma reflexão sobre as condições de produção de leitura de Pêcheux na França e no Brasil: os impasses lá e as necessidades cá.

\section{Análise de Discurso: entre a produção e a circulação do saber}

Pensar a Análise de Discurso nesse movimento inicial entre a produção e a circulação do saber sobre a linguagem é colocar uma problemática antiga em evidência: trata-se de uma tentativa de compreender e dar a conhecer a história da disciplinarização dos estudos sobre a língua no e do Brasil para tentar melhor apreender aquela própria à das regiões nas quais estamos vivendo e trabalhando, quais sejam, as regiões Sul e Sudeste do país. ${ }^{5}$ Por disciplinarização queremos "designer le processus

\footnotetext{
4 Essa primeira parte integra também o texto produzido por Scherer e Petri (2012), em capítulo de livro, que foi publicado na França e que vai ter lá um desenvolvimento diferenciado. Cabe ainda destacar que esse capítulo foi traduzido e publicado no Brasil na revista Desenredo, em 2013.

5 Petri e Medeiros (2013); Scherer e Petri (2013a); Mariani e Medeiros (2013); entre outros trabalhos que podemos citar sobre esse assunto.
} 
Amanda Eloina

Scherer

Lucilia

Abrahão Sousa

Vanise Medeiros

Verli Petri

(historique) parle le quel les propositons intellectuelles concernant le domaine consideré créent, reprennent et tentent de maîtriser la temporalité de leur développement"6 (PUECH, 2004, p. 125). Pretendemos saber mais sobre como os estudos sobre o funcionamento da disciplinarização desse saber podem carregar em sua história elementos importantes para se conhecer o desenvolvimento das Ciências da Linguagem em nosso território e para o imaginário de uma língua brasileira. $\mathrm{E}$, concomitantemente, como esse funcionamento pode se explicar pelas condições especiais de produção sobre a língua com os instrumentos linguísticos próprios ao nosso meio. Para nós, o estudo da disciplinarização deve levar em conta três aspectos: o primeiro, uma disciplina propriamente dita; o segundo, a constituição de um saber sobre a língua; o terceiro, a produção de instrumentos linguísticos que podem nos ajudar a refletir sobre esse saber como disciplina universitária (SCHERER, 2009). A proposta desse percurso tem por objetivo produzir uma reflexão mais ampla e, depois, situá-la de modo mais circunscrito, com vistas a marcar a relação da Análise do Discurso como campo disciplinar instituído.

\section{Por um terreno profícuo ao desenvolvimento de pesquisas}

Refletindo acerca de nosso trabalho, nós nos damos conta, igualmente, de como vão acontecendo os movimentos seguintes em nossas pesquisas, até chegar ao que fazemos atualmente. Destacamos, então, a importância dos trabalhos desenvolvidos pelos pesquisadores do Laboratório História das Teorias Linguísticas, sobretudo pelas pesquisas dirigidas por e sob a responsabilidade de Christian Puech. Fazemos parte de um grupo de pesquisadores brasileiros que visa introduzir as questões postas por essa equipe francesa e tenta aproximar, igualmente, nossos estudos a essa linha em específico. Observamos que o que propõe Puech (2004) para a história dos textos versus a história dos conceitos da disciplinarização ajuda-nos a elucidar a problemática sobre a qual nos debruçamos neste momento, dadas as diferentes designações (e aqui estamos fazendo referência à Análise de Discurso, Análise do Discurso, Análise Crítica do Discurso, Análise de Discurso Crítica etc. $\left.{ }^{7}\right)$ que as

\footnotetext{
6 "designar o processo (histórico) pelo qual as proposições intelectuais concernentes ao domínio con-
siderado criam, retomam e tentam didatizar a temporalidade de seu desenvolvimento" (tradução nossa).

6 "designar o processo (histórico) pelo qual as proposições intelectuais concernentes ao domínio con-
siderado criam, retomam e tentam didatizar a temporalidade de seu desenvolvimento" (tradução nossa). 7 Não é, contudo, o objetivo deste artigo discutir essa problemática. Remetemos, para esse propósito, a Scherer e Petri (2013b).
} 
concernem enquanto disciplinas institucionais consideradas "du triple point de vue de leur invention, de leur insertion dans une configuration plus large et de leur transmission: de la mise en forme 'savante' à la didactisation"8 (PUECH, 2004, p. 126). Como o autor nos ensina, é preciso levar em conta, igualmente, a escolha que o historiador deve operar entre a história conceitual e a história cultural da disciplina.

É preciso ressaltar que isso que apresentamos faz parte de um conjunto de resultados de nossas pesquisas desenvolvidas desde 2002 sobre a História das Ideias Linguísticas a partir dos trabalhos propostos pelo grupo da Universidade de Campinas (Unicamp), coordenado por Eni Orlandi e Eduardo Guimarães. Os trabalhos desses pesquisadores nos ajudam a compreender a institucionalização e a disciplinarização dos estudos sobre a língua, sobretudo em regiões do interior do Brasil; disciplinarização que funda inscrições teóricas e políticas na compreensão do que sejam língua e sujeito especialmente. É preciso sublinhar ainda que um campo disciplinar não existe sem uma instituição, como nos ensina Auroux (2007, p. 91): "sans institutions, les sciences et toutes les activités intellectuelles n'auraient ni histoire, ni même existence"9. No Brasil, para a disciplinarização da Análise de Discurso, seria necessário pensar em todos os obstáculos a superar no interior mesmo dos organismos de financiamento de pesquisa, como Capes e CNPq, que financiam a formação de pesquisadores e as pesquisas em si e que não veem ainda nosso trabalho como produção de conhecimento científico, nem no interior da Linguística nem fora dela. Essa contradição é totalmente natural em nosso cotidiano universitário como analistas de discurso, já que, como nos diz Courtine (1999, p. 18), “para trabalhar com a categoria de discurso, é necessário ser linguista e deixar de sê-lo ao mesmo tempo". Como então convencer os colegas, sobretudo no momento de avaliação, das nossas demandas de financiamento e de nossas necessidades enquanto programa de formação de jovens doutores? Essa é uma questão que permanece em aberto, sobretudo, porque se trata de um ato político de criar ou silenciar espaços, por (d)enunciar a língua e seu funcionamento e o sujeito que a ela se entrega.

\footnotetext{
8 "do triplo ponto de vista de sua invenção, de sua inserção em uma configuração maior e de sua transmissão: da formação 'erudita' à didatização" (tradução nossa).

9 "sem instituições, as ciências e todas as atividades intelectuais não teriam nem história, nem mesmo existência" (tradução nossa).
} 


\section{O pensamento de Michel Pêcheux: peças de memória da França para o Brasil}

Amanda Eloina

Scherer

Lucilia

Abrahão Sousa

Vanise Medeiros

Verli Petri que Pêcheux foi pouco lido em vida, mas que

son nom pourtant figure dans les bibliographies bien faites d'articles et de theses d'analyse du discours. C'est à cette discipline qu'il est en général associé. À juste titre. Mais ce qu'a pu represénter le discours dans sa pensée semble perdu. ${ }^{10}$

Ainda acerca dessa introdução que Maldidier faz do percurso do pensamento teórico de Pêcheux, interessa-nos a pergunta que inicia o parágrafo que se segue ao citado anteriormente: "Lire Michel Pêcheux aujourd'hui?".

Por que destacar esses dois fragmentos? De imediato, como já é sabido, Pêcheux é lido no Brasil. Deveras! Talvez a produção brasileira com referência a Pêcheux - teses, artigos, congressos, livros etc. - seja maior que aquela hoje existente na França. E isso nos leva a deslocar a pergunta de Maldidier: por que se lê muito Pêcheux no Brasil? Como interpretar a escolha de tantos pesquisadores que se dedicam a ler, estudar e fazer avançar o dispositivo teórico-analítico engendrado por ele na interlocução com seus pares? Ou talvez devêssemos dar andamento às nossas reflexões nos interrogando sobre o estupor, a surpresa, as interjeições que pontuam a fala de um ou outro quando se diz que se lê, e muito, Pêcheux no Brasil.

Orlandi (2011, p. 13), ao refletir sobre a "recepção" da obra pechetiana no Brasil, explicita que "não se recebe simplesmente um autor", pois há o estabelecimento de "uma relação com a obra desse autor, sempre a partir de uma posição nossa em nossa tradição de reflexão e na história do conhecimento que produzimos no Brasil". Ler Michel Pêcheux no Brasil hoje, acrescentaríamos, “é preciso”, parafraseando o poeta português (Fernando Pessoa), que dizia que "navegar é preciso, viver não é preciso". Trata-se de uma conjuntura social, histórica e discursiva que interpela intelectuais de diferentes áreas da produção do conhecimento a "navegar", a conhecer os processos de produção de

10 "seu nome no entanto figura nas bibliografias bem feitas de artigos e teses em Análise de Discurso. É a essa disciplina a que ele é associado em geral. Com razão. Mas o que o discurso pode representar em seu pensamento parece perdido." (tradução de Eni Orlandi). 
sentidos e a não se satisfazer com os produtos dados como prontos, supostamente evidentes, completos, consumíveis.

Para nós, ler Pêcheux é seguir navegando no sentido de que temos a necessidade de singrar outros mares, de construir com Pêcheux

O lugar dos estudos franceses na constituição de uma memória da Análise de Discurso no Brasil língua) ou, no dizer de Orlandi (2011, p. 14-15), propor "uma retomada. Mas, como está na própria análise de discurso, retomar não é repetir. Repetir não é reproduzir. [...] Propomos, pois, ler esses textos em sua história presente".

Por que uma presença tão forte se evanesceu a ponto de ser ausência no meio acadêmico? Trata-se de uma pergunta que nos coloca, brasileiros pesquisadores leitores de Pêcheux, em um passado ou em um futuro. De qualquer forma, ambas as possibilidades nos jogam fora do tempo presente. Para nós, a pergunta deve ser outra: por que seu pensamento foi e continua sendo tão profícuo no Brasil? Uma primeira possível resposta se encontra no texto de Maldidier (1990, p. 7): “Au-delà de son inscription historique dans une époque et un langage qui sont déjà loin de nous, la pensée de Michel Pêcheux est une pensée forte."12

Um pensamento forte é uma justificativa, mas isso levaria a não se deixar de lê-lo em outros lugares. Não somos ingênuos; sabemos que um pensamento teórico tem condições de produção para se fazer ouvir, para ecoar e vicejar. E tais condições têm ligação com o modo como (des)arrumar as relações de poder do que deve e pode ser pesquisado, do que deve e pode circular nos espaços de pesquisa e nas instituições universitárias. Para além de um pensamento forte, no Brasil, deparamo-nos com condições de produção favoráveis aos estudos do discurso.

11 "condição de possibilidade da AD, mas também uma das modalidades de sua existência" (tradução nossa).

12 "Para além de sua inscrição histórica em uma época e uma linguagem que já estão longe de nós, o pensamento de Michel Pêcheux é um pensamento forte.” (tradução de Eni Orlandi). 
Amanda Eloina

Scherer

Lucilia

Abrahão Sousa

Vanise Medeiros

Verli Petri

O grupo de pesquisadores interessados em uma teoria do discurso não cessa de aumentar e de se reinventar para fazer avançar a produção do conhecimento que iniciou com Pêcheux e seus interlocutores na França do final da década de 60 até o início da década de 80 . Travessa pelo sertão da linguagem que continua a produzir efeitos e a fazer valer o trajeto em construção, em curso, em discurso.

Arriscamos ainda outra resposta a nossa pergunta: porque em Pêcheux é central e diferencial um conceito - o de ideologia. Segundo Paul Henry ${ }^{13}$, Pêcheux, ao buscar entender o que é e como funciona a ideologia, deparou-se com o discurso. Refletir sobre ideologia e discurso é ocupar-se da questão da produção de sentidos e de efeitos de sentido. À ideologia Pêcheux relacionou a noção de sujeito - ambos, como lembra Zoppi-Fontana (2005), com estatuto teórico e político. Esses dois pilares entrelaçados - ideologia e sujeito - colocam em cena o que radicalmente modifica os estudos da linguagem, fazendo falar uma instância tão assustadora quanto subversiva para a teoria: as instâncias do poder e do inconsciente. E tocar na questão do sujeito não é tarefa fácil, sobretudo porque implica o próprio pesquisador, que, assujeitado à ideologia, passa a saber de seus limites na relação institucional, passa a analisar criticamente os modos de naturalização dos sentidos em dada posição e passa a recusar qualquer efeito de obviedade nos (f)atos de língua(gem).

O discurso implica práticas sociais e delas não pode ser desvencilhado. É ao estabelecer essas relações que Pêcheux coloca o homem em relação com a história, o que, dito de outra forma, significa compreender que o sujeito se constitui no discurso, interpelado ideológica e historicamente e sob a inalienável condição de ser dotado de inconsciente. Assim, a noção de história passa a compor o aparato fundamental, já que para nós ela consiste no "fazer sentido" (HENRY, 1994, p. 52). Não há necessidade de julgamento sobre se está certo ou errado, se é gramatical ou agramatical, se está de acordo com nossos princípios éticos e/ou com nosso posicionamento político; o importante é compreender como se produz esse sentido e não outro.

Para um campo que trabalha com as regularizações e que se estrutura pela repetição e categorização, tal contorno é da ordem do insuportável. E talvez o tenha sido também para Pêcheux e para nós.

13 Em conferência no Sead, em Porto Alegre, 2011. 
Mas um insuportável que nos parece indicar um caminho para mais intensamente acolher o que é da linguagem e do humano: a opacidade e a incompletude. 0 trabalho nas fronteiras, nas linhas que entrecruzam campos epistemológicos, já é por si só uma empreitada trabalhosa, mais ainda quando o que se constrói não é uma soma de traços que se agrupam ou se acrescentam tal e qual eram postos nas teorias originais, ou ainda quando o teórico os desloca e os "reinventa" a partir de uma inscrição própria. Um trabalho, portanto, nos entremeios, no litoral de ver roçar os movimentos da língua na história, sustentado pelo sujeito em dada posição que constrói o estofo conceitual e nos convoca a atravessar a evidência do sentido único.

Para nós, analistas brasileiras, esse foi o caminho de Pêcheux: nas trilhas de (des)encontros, em zonas de litoral, na tênue linha dos em-

O lugar dos estudos franceses na constituição de uma memória da Análise de Discurso no Brasil préstimos que, depois de tomados, passam a ser outro(s). Pêcheux nos obriga a manejar conceitos do materialismo dialético, da língua e do inconsciente, apreendendo-os de modo outro pelo qual são atravessados pelo sujeito como posição no discurso e pela ideologia como processo de criação de evidências para os sentidos do mundo. É a desconstrução do efeito de evidência que nos move. A Análise de Discurso nos seduz não pela possibilidade de revelar algo ainda não dito, mas porque nos proporciona a explicitação de processos discursivos que se apagam para que apenas o produto tenha visibilidade, atendendo já a uma demanda da formação ideológica dominante. Os traços estão em algum lugar que o movimento de análise faz emergir, estão lá como constitutivos do processo; nada escondido a ser descortinado, apenas processos. Processos políticos, acima de tudo, de dizer e de se inscrever na língua.

\section{Impasses lá; desafios cá}

Vejamos um ponto que nos parece nodal na tentativa de responder às questões que fizemos no início deste escrito: para compreender o esforço do pensamento teórico de Pêcheux, é preciso teorizar sobre o poder e o desejo, e tais temas não são apaziguadores. Dizer isso na França dos anos 1970 era produzir fissuras na ordem vigente, instalando vozes reivindicatórias de então e fazendo bater os teares do discurso no tecido de novas provocações e deslocamentos. Gadet (2004, p. 12), no prefácio da edição brasileira de A língua inatingível, diz-nos de um projeto "intelectualmente ambicioso" de "retornar àquilo que os anos 1970 e 1980 representaram na França, anos de esperança, sob os aspectos 
Amanda Eloina

Scherer

Lucilia

Abrahão Sousa

Vanise Medeiros

Verli Petri intelectuais, culturais e políticos". E mais, a autora afirma que "a manutenção do fio de Ariadne de uma incontornável materialidade da língua, bem frisado no texto de Denise Maldidier, é o que traz uma certa beleza, mas talvez também a utopia - sempre graças ao recuo - do primeiro livro de Pêcheux" (p. 13). É preciso observar que "esperança", uma vez tomada por Gadet como utopia, não é um significante qualquer, porque coloca em xeque uma Linguística formalista preocupada com as "decisões administrativas sobre a organização do ensino da gramática" (GADET; PÊCHEUX, 2004, p. 20) ou com certa "Linguística da frase", como afirmam os autores em relação ao gerativismo.

Produz-se, assim, um campo de desacordo com os estudos em curso à época e se insere o político no campo das teorizações, criando uma teoria que toma o poder, que está sempre em jogo no confronto entre classes sociais e o poder dizer que instala o sujeito à condição desejante. Dessa forma, provocam-nos a questionar e duvidar da língua das instituições, do direito, da política, da vida administrativa das instituições, dos partidos e dos projetos políticos. E nos fazem seguir questionando e investigando a língua da mídia, da informática, da medicina, das ciências etc., para relembrar Pêcheux, a língua de ferro, de madeira, de vento. Ainda, como nos alertam Gadet e Pêcheux (2004, p. 23),

\footnotetext{
as máquinas lógicas fabricam, hoje em dia, suas próprias memórias para melhor apagarem as do povo, e para melhor administrarem os complexos industriais, administrativos e militares que vão tomar as decisões no lugar delas.
}

E o fazem para que pensemos em discurso, língua discursivizada em dada posição em relação ao poder, em que pese o modo como certos sentidos são naturalizados e outros são apagados, ou seja, língua circunstanciada pelo sujeito na trama sócio-histórica.

Se, na época de sua fundação teórica, o fervor das movimentações políticas estava a alavancar na França grandes rupturas com o poder político vigente, é certo que os sentidos estabilizados e marcados por um Estado de bem-estar social foram sendo construídos, com certa eficácia, em relação ao acesso básico à saúde e à educação, entre outros.

No Brasil, por sua vez, a ditadura política inscrevia um cenário em que tais sentidos não podiam circular sob o peso da censura e violência de Estado. Campo fértil para os estudos formalistas, que insistiam 
em apagar o sujeito e a história, e de par com uma inscrição duplamente positivista: por um lado, da Linguística como ciência - isso para ambos os países -, mas, por outro, de par com os estudos também de inscrição positivista sobre a língua no Brasil (ORLANDI, 2002). Campo que foi tomado como minado à proposta de Pêcheux, poder-se-ia pensar se a própria teoria não indicaria a falha como constitutiva do ritual.

Falha que aponta para a resistência - não apenas como resposta, revolta, rebelião, mas também como resistência à e da língua - na direção sinalizada pelo próprio Pêcheux no caso do acontecimento discursivo "On a gagné", quando o jogo da língua marca o fluxo dos efeitos de vitória em deslocamento do campo esportivo para o político. O que chama a nossa atenção é que foi em condições históricas marcadas pelo impedimento de dizer sobre língua e discurso e pela impossibilidade de

O lugar dos estudos franceses na constituição de uma memória da Análise de Discurso no Brasil teorizar sobre sujeito e ideologia que essa teoria germinou no Brasil. Com a abertura política do final dos anos 80 , os efeitos do pensamento pechetiano ganharam inscrição e corpo institucionais com o trabalho de Eni Orlandi em São Paulo; e, de lá, saem pesquisadores que vão orientar outros trabalhos em diferentes universidades do Brasil difundindo as ideias de Pêcheux. Esses trabalhos se encontram com outros advindos de pesquisadores com formação em Linguística francesa, como é o caso de pesquisadores da Universidade Federal de Santa Maria, para ficarmos em um exemplo no qual Jean Peytard e Michel Pêcheux puderam dialogar. Importa destacar que outros autores do círculo de Pêcheux, como Paul Henry, Maldidier, Mazière e Authier-Revuz, fazem-se presentes na sustentação teórico-metodológica da Análise de Discurso no Brasil. Redes foram se formando a partir do pensamento de Pêcheux e de questões ao pensamento de Pêcheux.

Os acontecimentos do Brasil nos anos 1990, para nosso trabalho, funcionam como segundo momento de demanda social e de interpelação do sujeito analista. A sociedade brasileira quer mais do que a abertura democrática, do que as eleições diretas para a presidência da República; há um desejo crescente de que a esquerda chegue ao poder e, se isso se deu na França dos anos 1980 com François Miterrand, dá-se no Brasil com Luís Inácio Lula da Silva vinte anos depois. O grito do povo nas ruas não é “on a gagné", mas o povo segura o grito e espera a palavra do metalúrgico que chega ao poder e que, em plena Avenida Paulista, sobe num palco improvisado para dizer ao Brasil e ao mundo: "Agora o povo está no poder!”. Aí sim se ouve a voz das massas nas ruas: “O povo está no poder!”. 
Não estamos mais naquele momento de êxtase, é preciso lembrar. A primeira década dos anos 2000, nosso terceiro momento aqui

Amanda Eloina

Scherer

Lucilia

Abrahão Sousa

Vanise Medeiros

Verli Petri destacado, é plena de acontecimentos, desencadeando na atualidade movimentos sociais nunca antes vistos, sobretudo em 2013, com todas as manifestações que levaram para as ruas do país um grito de "não" diante do aumento da tarifa do ônibus: não ao abuso, ao jogo de mercado das prefeituras com as empresas de transporte, não ao serviço ruim prestado à população pobre. Depois outros gritos de "não" se manifestaram na polissemia e heterogeneidade que, constitutivas da linguagem, explodiram à moda de manuscritos em cada cartaz, em cada protesto.

Num primeiro momento, pela inquietude dos conceitos e do arcabouço teórico da Análise de Discurso de Pêcheux, tal inscrição passou a dialogar com a vida dentro e fora da academia, aquela vida turbilhonada pelos sentidos de mudanças políticas tão necessárias ao nosso momento: era a hora de dizer da liberdade, de questionar o autoritarismo de Estado, de tomar as ruas, de reclamar os desaparecidos políticos, de movimentar os sinais de um país desejoso de ser mais participativo, enfim, de arrancar esperança do futuro. É hora agora de tomarmos o pensamento de Pêcheux na sua mais profunda radicalidade para dizermos sim à língua no rebuliço da história, não aquela que se ensinava nos colégios e que consistia em uma recitação de regras impostas, mas a língua da rua, do povo, dos trabalhadores em greve, dos estudantes em passeatas, dos intelectuais e artistas nas manifestações, ou melhor, de todos aqueles que queriam e querem dizer não à ordem estabelecida pela coerção, tortura e violência.

Há um grupo que já não aceita o funcionamento do Estado na implementação da política do consenso - não há consenso num país com tantas desigualdades sociais -, e é também em Pêcheux que vamos encontrar subsídios teóricos e analíticos para o trabalho de explicitação da contradição. Aqui estamos pensando a contradição própria ao sujeito e própria ao Estado. As manifestações públicas atuais reivindicam espaço para o singular, o diferente, buscando um lugar para a contradição como constitutiva e não como algo a ser selecionado, esquecido, camuflado, combatido, apagado. Observa-se então que o espaço para os contradiscursos é outro. Apesar da tagarelice das mídias, que, ensurdecendo, cortam mais que as "línguas de ferro", os analistas de discurso são interpelados pelas militâncias de uma causa maior que pode e deve ser ouvida em diferentes instâncias. 
Se o início dos trabalhos de Pêcheux, na França, é marcado pelo interesse em discursos políticos, no Brasil, podemos dizer que há uma diversidade de discursos que interessam ao analista, não havendo preocupação com uma tipologia discursiva ou com qualquer outra forma de classificação. É tempo de ampliação; é tempo de contemplar diferentes materialidades discursivas. É preciso recuperar o que Orlandi avança em relação à crítica necessária feita por Courtine e Marandin (1981) quando denunciam um certo trabalho com a teoria para leitura tão somente de textos políticos. Para Orlandi (2004, p. 10), "Isto nos leva mais longe pois é um passo importante na compreensão da relação entre o simbólico e as relações de poder (e não a mais a maquinaria linguística e os textos políticos)."

Em outras palavras, o político - entendido aqui como divisão de

O lugar dos estudos franceses na constituição de uma memória da Análise de Discurso no Brasil sentidos, conforme Guimarães (2007) - passa a funcionar como uma noção constitutiva da teoria sendo observável em diferentes materialidades: imagens, fotografias, pichações, grafites, tatuagens, cinema, literatura, música etc.

\section{Por uma pausa na reflexão que não cessa...}

À guisa de reflexões finais, parece-nos muito indiciário que o adormecimento do pensamento pechetiano na França tenha início no mesmo momento em que esteja em trabalho de parto no Brasil: duas temporalidades que, na diacronia, inscrevem estados absolutamente díspares. 0 que não se pode mais avançar em um lugar - pelo recalque que a própria morte do autor impõe, pois sabemos que, em termos lacanianos, o significante da morte é perdido para sempre - é trabalho que nos cabe do lado brasileiro. Uma empreitada teórica que nos chama(va) à vida de um outro modo diferente daquele em que éramos obrigados a sobreviver e cuja França dos anos 60/70 sinalizava ser possível conquistar.

Se todo leitor é marcado por uma fome, como lemos em nossa epígrafe, e essa fome é diferente para cada um, podemos agora talvez dizer que havia, no Brasil, uma fome de poder dizer e de fazer dizer que nos fez ler Pêcheux e com ele ousar pensar. Não é, de fato, uma teoria para supostos tempos felizes, dado que permite observar o funcionamento das ilusões que parecem sustentar o chão em que pisamos, e também fraturá-las para que elas deixem de ter a evidência que as fazia absolutas. Eis, então, uma teoria que joga areia nas engrenagens óbvias, fazendo furos no que estava semanticamente estabilizado como único modo de dizer. 


\section{Referências}

Amanda Eloina

Scherer

Lucilia

Abrahão Sousa

Vanise Medeiros

Verli Petri

AUROUX, Sylvain. La question de l'origine des langues suivi de l'historicité des sciences. Paris: Quadrige/PUF, 2007.

CASTELlo, José. Coluna do Castello. o Globo, Rio de Janeiro, 27 fev. 2010.

COURTINE, Jean-Jacques. O chapéu de Clémentis. Trad. de Marne Rodrigues de Rodrigues. In: INDURSKY, F.; FERREIRA, M. C. L. (Org.). Os múltiplos territórios do discurso. Porto Alegre: Sagra Luzzato, 1999. p. 15-22.

; MARANDIN, Jean Marie. Quel object pour l'analyse du discours? In: Matérialités discoursives. Colloque de 24, 25 e 26 avril, 1980. Nanterre: Presses Universitaire de Lille, 1981.

GADET, Françoise. A língua inatingível: o discurso na história da linguística. Trad. de Bethania Mariani e Maria Elizabeth Chaves de Mello. Campinas: Pontes, 2004. p. 11-15.

; PÊCHEUX, Michel. A língua de Marte. In: A

língua inatingível: o discurso na história da linguística. Trad. de Bethania Mariani e Maria Elizabeth Chaves de Mello. A língua inatingível: o discurso na história da linguística. Trad. de Bethania Mariani e Maria Elizabeth Chaves de Mello. Campinas: Pontes, 2004. p. 19-26.

GUIMARÃES, Eduardo. Sémantique et grammaire: une histoire des études linguistiques au Brésil. In: ORLANDI, E.; GUIMARÃES, E. (Dir.). Un dialogue atlantique: production des sciences du langage au Brésil. Lyon, France: ENS Editions, 2007. p. 11-35.

HENRY, Paul. A história não existe? Trad. de Bethania Mariani et al. In: ORLANDI, E. et al. (Org.). Gestos de leitura: da história no discurso. Campinas: Ed. da Unicamp, 1994. p. 29-52.

MALDIDIER, Denise. L'inquiétude du discours. Paris: Ed. des Cendres, 1990. 
MARIANI, Bethania; MEDEIROS, Vanise. Disciplinarização dos estudos em Análise de Discurso. Revista Gragoatá, Instituto de Letras, Universidade Federal Fluminense, n. 34, p. 15-25, 1ํsem. 2013.

ORLANDI, Eni. Língua e conhecimento linguístico: para uma história das idéias no Brasil. São Paulo: Cortez, 2002.

Cidade dos sentidos. Campinas: Pontes, 2004.

Ler Michel Pêcheux hoje. In: Análise de Discurso: Michel Pêcheux. Textos selecionados. Trad. de Eni Orlandi et al. Campinas: Pontes, 2011. p. 11-20.

O lugar dos estudos franceses na constituição de uma memória da Análise de Discurso no Brasil

PÊCHEUX, Michel. Ler o arquivo hoje. In: ORLANDI, E. et al. (Org.). Gestos de leitura: da história no discurso. Trad. Bethania Mariani et al. Campinas: Ed. da Unicamp, 1994. p. 55-64.

PETRI, Verli; MEDEIROS, Vanise. Da língua partida: nomenclatura, coleção de vocábulos e glossários brasileiros. Letras, Santa Maria, v. 23, n. 46, p. 43-66, jan./jun. 2013.

PUECH, Christian. Antinomies (V.Henry) et Dichotomies (F. de Saussure) l'idée d'une science Double - dans la linguistique générale de la fin du XX siècle. In: Linguistique et partages disciplinaires à charnière dês XX siècles: Victor Henry (1850-1907). Louvain-Paris, Editons Peeters, Bibliothèque de l'Information Grammaticales, n. 55, p. 125-150, 2004.

SCHERER, Amanda Eloina. Dos domínios e das fronteiras: o lugar fora do lugar em outro e mesmo lugar. In: SARGENTINI, V.; GREGOLIN, M. R. (Org.). Análise do discurso: heranças, métodos e objetos. São Carlos: Claraluz, 2009. p. 131-142.

; PETRI, Verli. Le mouvement et les déplacements des études sur le discours à partir des années 1980 et leur disciplinarisation: le cas brésilien. In: PUGNIÈRE-SAAVEDRA, Frédéric; SITRI, Frédérique; VENIARD, Marie (Ed.). Analyse du discours dans la societé: engagement du chercheur et demande social. Paris: Éditions Champion, Honoré Champion, 2012. v. 1, p. 55-65. 


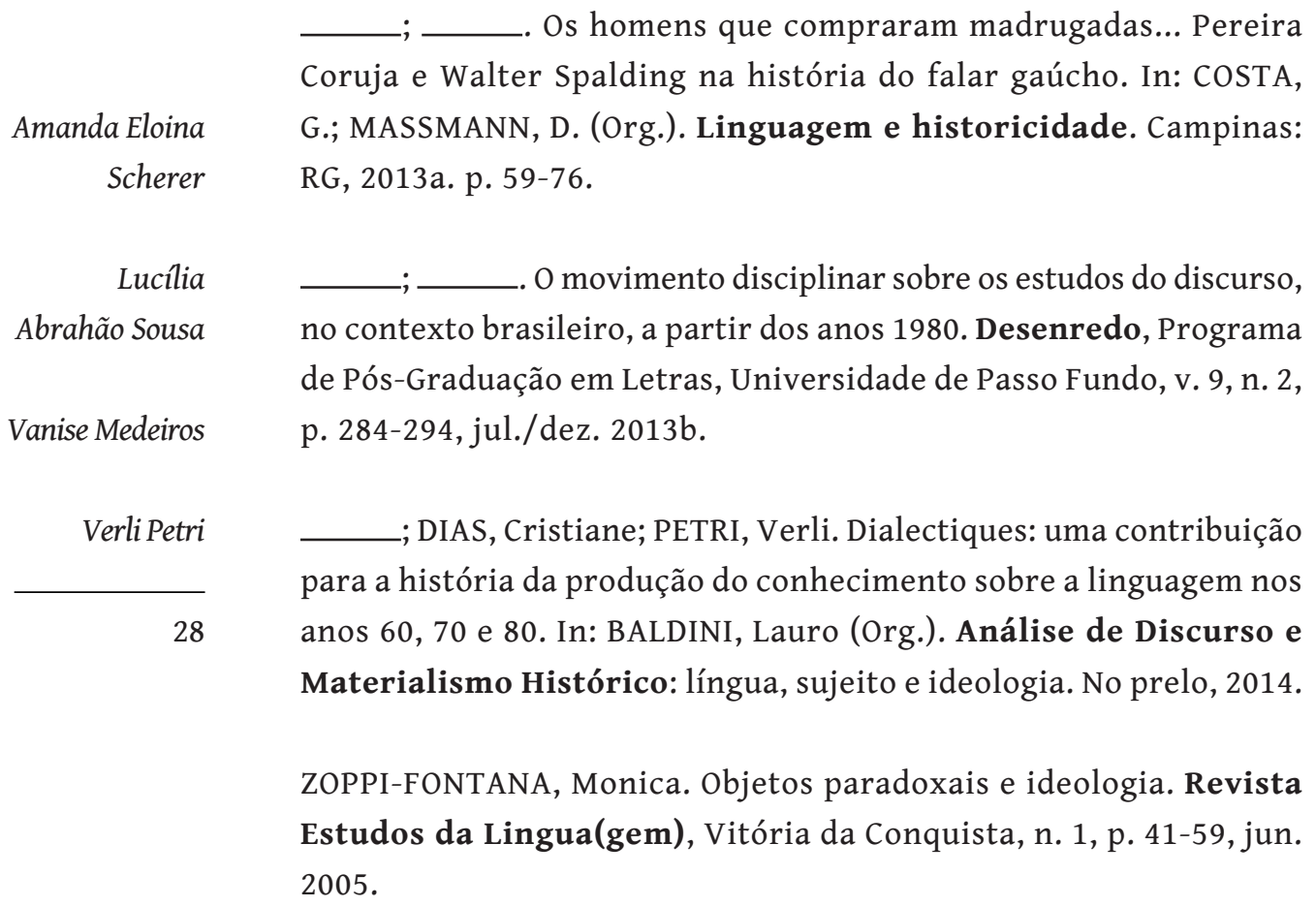

